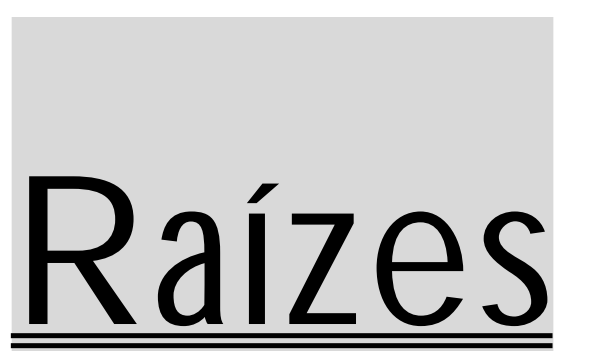

v. 28, ns. 1 e 2, jan. - dez./2009; v. 29, n. 1, jan. - jun./2010

D ossiê: Território, sustentabilidade e ação pública

( $M$ arc Piraux, Márcio Caniello - O rgs.)

\title{
ARTICULAÇÃO ENTRE OS DIFERENTES COMPONENTES DA SUSTENTABILIDADE AGRÍCOLA ${ }^{1}$
}

\author{
Jean $M$ arc van der Weid
}

\section{RESU M O}

A definição desustentabilidade na agriculturaé bastantefal ha por não incluir o uso de recursos naturais não renováveis. Ao incluirmosna análiseda sustentabili idadeagrícola a disponibilidade futura de petróleo, gás, fósforo epotássio constataremos que o esgotamento do modelo agrícola oriundo dachamada "Revol ução Verde" está muito próximo. Se incluirmosna equação os impactos diretos eindiretos deste model o nos recursos naturais renováveis (solos, água e biodiversidade) eno clima, a sustentabilidadefica ainda mais discutível. Final mente, setratarmos dos impactos sociais do avanço destemodel o no campo (pelo esvaziamento) enas cidades (pelo inchaço) teremos um quadro devastadore altamenteperigoso para o futuro dahumanidade.

Palavras-chave: sustentabilidade agrícola, recursos naturais renováveis, campesinato.

\section{ART ICULATE THE DIFFERENT DIMEN SIONS OF AGRICULTURAL SUSTAINABILITY}

\begin{abstract}
A BST RAC T
The definition of sustainability in agriculturefails by not including the use of non renewed natural resources. Including in theanalysis of agricultural sustainability the avail ability of oil, gas, phosphorusand potassium in a future, wefind that the depletion of the agricultural model derived from the "Green Revolution" is very close. If we include in theequation model the direct and indirectimpacts in renewablenatural resources (soil, water and biodiversity) and climatesustainability itbecomes even more questionable. Finally, if we treatthis model with the social impacts of development in rural areas (by emptying) and cities (by the swelling), we havea devastating and highly dangerous set for the futureof humanity.
\end{abstract}

Key words: agricultural sustainability, renewablenatural resources, peasants.

Jean Marcvan der Weid. Coordenadordo Programa dePolíticas PúblicasdaAS-PTA. Email: jean @ aspta.org.br

1 Texto apresentado no Seminário Internacional "D esenvolvimento Sustentável e Territórios Rurais: Quais desafios para a ação pública”, organizado pelo Cirad, a U niversidade Federal de Campina Grandee a Fundação U niversidade Camponesa realizado em Campina Grande/PB no período de22 a 25/09/2009. 


\section{O QUe É "desenVOlVImento agrícola sustentável"?}

É intrigante a dificuldade de se consolidar um conceito que seja aceito de forma universal. M ais difícil ainda é ver a aplicação do conceito para avaliar os vários sistemas de produção que caracterizam a agricultura brasileira e, por extensão, as políticas públicas que os suportam ou inibem.

0 conceito de sustentabilidade consagrou-sena Conferência das $\mathrm{N}$ ações Unidas para o meio ambiente e 0 desenvolvimento em 1992. Ao longo da década a FAO (Food and Agriculture O rganization of the $\mathrm{U}$ nited $\mathrm{N}$ ations) e o CGIAR (C onsultative Group on International Agricultural Research), assim como inúmeras outras instituições relacionadas com a agricultura buscaram aplicar o conceito (nas suas várias formulaçōes) para o desenvolvimento agrícola. Algumas das definições mais consagradas para este conceito são:

1. Segundo a FAO; "agricultura sustentável é o manejo e conservação de recursos naturais e a orientação de mudanças tecnológicas e institucionais de maneira a assegurar a satisfação das necessidades humanas de forma continuada para a presente e para as futuras gerações. Tal desenvolvimento sustentável conserva o solo, a água e os recursos genéticos animais e vegetais; não degrada o meio ambiente; é tecnicamente apropriado, economicamente viável e socialmente aceitável".

2. Segundo o C GIAR; "agricultura sustentável é o manejo bem sucedido de recursos para a agricultura de modo a satisfazer as necessidades humanas em transformação, mantendo ou melhorando, ao mesmo tempo, a qualidade do ambiente e conservando os recursos naturais".

3. A Sociedade Americana de Agronomia (ASA), por exemplo, utiliza a seguinte definição: "A agricultura sustentável deve, no longo prazo, melhorar a qualidade ambiental e os recursos básicos dos quais a agricultura depende, respondendo às necessidades humanas básicas de alimentos e fibras, sendo economicamente viável e melhorando a qual idade de vida dos agricultores e da sociedade como um todo".

É interessante observar que em todas as definições não se faz referência aos recursos naturais não renováveis, com a ênfase sendo voltada para os renováveis: solo, água e recursos genéticos. Apenas a definição do C GIAR deixa pairar a dúvida sobre a inclusão dos recursos naturais não renováveis por não ter especificado a que recursos naturais se referem. $\mathrm{N}$ o entanto, o mero fato de propor a conservação dos recursos naturais indica que, implicitamente, a referência é aos renováveis. Por definição, os recursos naturais não renováveis não podem ser conservados a não ser que não sejam utilizados e, neste caso, não seriam mais recursos.

É explicável que, no contexto da ECO 92, a ênfase sobre os recursos naturais renováveis, diretamente relacionados com os temas ambientais, fosse dominante. 0 curioso é que, desde então, pouco tenha sido acrescentado aos conceitos de desenvolvimento agrícola sustentável para incorporar a questão dos recursos naturais não renováveis.

\section{OS RECURSOS NãO REN OVÁVEIS E A ART IFICIALIZAÇÃO DA AGRICULTURA}

É claro que nenhum analista, de qualquer orientação ideológica, política ou científica, ignora que o modelo de desenvolvimento agrícola dominante no Brasil e no mundo, apelidado de agronegócio aqui e agrobusiness lá, é total mente dependente de recursos naturais não renováveis tais como petróleo, gás, fósforo e potássio. Este modelo também depende, é claro, dos recursos naturais renováveis - solo, água e recursos genéticos e das condições ambientais para a produção como luz, calor, chuva e ventos bem como das reações das outras espécies vegetais e animais aos esforços humanos de privilegiar as espécies cultivadas. No entanto, o modelo do agronegócio evoluiu a partir de um paradigma da busca da máxima artificialização possível do meio ambiente para poder controlar o processo produtivo.

N este paradigma, as necessidades básicas para uma planta se desenvolver são controladas artificialmente. N utrientes e água não vem dos solos e da chuva, mas de adubos químicos e irrigação. 0 próprio solo é tratado apenas como suporte da planta e, idealmente, substituído por substratos inertes servindo apenas à fixação das raízes. L uz, ventos, umidade e calor buscam ser controlados em sistemas de estufas que também buscam isolar as plantas de insetos, doenças e plantas competidoras por controles químicos. A própria natureza das plantas passou a ser alterada artificialmente por manipulações genéticas introduzidas pela biotecnologia.

0 processo de artificialização das condições de produção agrícola estancou no nível do controle da oferta 
de água e nutrientes bem como das plantas concorrentes (chamadas ervas "daninhas" ou "invasoras"), insetos e patógenos. 0 controle da temperatura e dos ventos exigiria um investimento gigantesco para colocar a agricultura entre 4 paredes e um teto e só foi utilizado para produtos de alto valor e mesmo assim em condições muito especiais.

O s esforços de controle da oferta de água e nutrientes, a defesa das espécies cultivadas contra pragas, doenças e invasoras e a sua manipulação genética cobram um uso maciço de recursos naturais não renováveis, quer na forma de insumos, quer pela demanda de energia na sua produção e uso. Por outro lado, o agronegócio se caracteriza também por buscar a máxima mecanização das operações agrícolas, minimizando o uso de outro recurso natural renovável - o trabalho humano. M ecanização implica em uso de combustíveis, quer para produzir, quer para operar as máquinas.

Como seria inimaginável ignorar a dependência do agronegócio dos recursos naturais não renováveis, por que estes nunca aparecem nas definições de sustentabilidade? Por definição, os recursos naturais não renováveis se esgotarão em algum momento e, portanto, qualquer sistema que del es dependa é insustentável. A única razão da não incorporação dos recursos naturais não renováveis na definição da sustentabilidade da agricultura seria a existência de reservas tão amplas destes recursos, que colocassem o problema do seu esgotamento para um futuro tão remoto que não valeria a pena ser considerado no momento.

A parentemente, os vários operadores do agronegócio, bem como analistas de vários tipos, estão vivendo nesta crença nos recursos "inesgotáveis". A outra hipótese seria a de que estão buscando tirar o máximo de lucros com o sistema do agronegócio enquanto ele durar, e pouco se importando com o que vai acontecer depois.

A realidade é que o esgotamento dos recursos naturais não renováveis essenciais para a agricultura e para a economia como um todo não é esperada em um futuro remoto e sequer para as próximas gerações. É para hoje e até para ontem.

O conceito de "peak oil" ainda não chegou ao Brasil ou, pelo menos, está muito longe da mídia. Ele foi definido pelo geógrafo americano $\mathrm{H}$ ubbert (citado por Porto, 2006) que, em 1956, predisse que o petróleo americano alcançaria o seu "pico de produção" em 1970, seguindo-se um declínio inexorável à medida que as reservas iriam se esgotando. $\mathrm{H}$ ubbert não foi levado a sério, mas sua previsão foi matemática, o "peak oil" nos EUA ocorreu em 1970. H ubbert tinha informações menos precisas sobre as prospecções de petróleo no mundo, as reservas reais existentes e a taxa de extração dos diversos poços. Além disso, ele não podia prever os avanços tecnológicos que permitiram ampliar a extração ou mesmo explorar poços em águas ultraprofundas, como o pré-sal brasileiro. Assim, a sua previsão de que o "peak oil" mundial ocorreria na virada do século não se confirmou.

Três dos mais renomados especial istas em petróleo, não vinculados às empresas do setor, refizeram recentemente os cálculos de $\mathrm{H}$ ubbert com dados mais precisos e atual izados e constataram que 0 americano errou por pouco. Segundo eles, o "peak oil" mundial iria ocorrer entre 2006 e 2010, ou seja, já deve ter ocorrido (T verberg, 2008).

Alcançar o "pico de produção" não significa que os volumes extraídos vão cair imediatamente, mas que quanto maior a extração a partir deste ponto, mais rápido as reservas se esgotarão e mais abrupta será a queda de produção. Por outro lado, a partir do pico, os custos de extração vão ficar cada vez mais elevados na medida em que os poços de mais fácil exploração vão se esgotando mais rápido.

A explosão dos preços do petróleo, que alcançou 0 valor recorde de 140 dólares por barril em jul ho de 2008, para desabar para perto de $30 \mathrm{USD} /$ barril no final do ano, foi interpretada pelo presidente Lula como mera especulação das empresas petrolíferas. É claro que houve especulação, mas ela se deu sobre uma tendência de alta constante do preço do petróleo, que subiu $180 \%$ em 16 meses. Tanto a alta como a queda dos preços do petróleo teve pouco efeito sobre a oferta e a demanda do produto, e isto apesar da crise ocorrida no segundo semestre de 2008 e da qual o mundo ainda não se recuperou. E mbora a economia mundial tenha estancado 0 preço do petróleo, ele já subiu para perto de 100 dólares por barril desde o "fundo do poço" no início do segundo semestre de 2008 (Zimmermann, 2008).

A verdade é que a dependência da economia mundial, em relação ao petróleo, é tão forte que os crescentes desbalanços de oferta e demanda vão gerar oscilações de preço freqüentes e abruptas, amplificadas pela especulação.

O Brasil passou a crise do preço do petróleo dormin- 
do em berço esplêndido e sonhando com o pré-sal, pois a Petrobras não repassou os preços internacionais para os consumidores brasileiros. N os EUA, o custo de encher o tanque do carro quadruplicou no período, implicando um gasto extra total para os motoristas de 300 bilhões de dólares só no primeiro semestre de 2008. Alguns economistas apontam para este gasto extra como o catalisador da inadimplência que atingiu o setor de renda médio baixa nos EUA e quebrou as imobiliárias, seguradoras e bancos na chamada crise do "sub-prime".

Além do consumidor e da economia brasileira não terem sentido os efeitos dos preços internacionais do petróleo, estamos vivendo uma euforia estimulada pelo governo e pela mídia, que colocam as reservas do présal como equivalentes às das grandes empresas petroleiras do mundo.

As reservas do pré-sal estão estimadas em 80 bilhões de barris, mas a Petrobras não divulgou se este é o volume que se pode extrair ou se é o volume total. No segundo caso, a disponibilidade de petróleo será muito menor já que a taxa de extração para poços deste tipo é de 35 a 40\%. M esmo com mais avanços tecnológicos no futuro dificilmente a taxa de extração será maior do que 50 a $60 \%$.

M esmo supondo que a reserva disponível seja de 80 bilhões de barris, ela representa apenas dois anos da demanda mundial de petróleo prevista para 2030. Os especial istas independentes, acima mencionados, prevêem que a produção mundial de petróleo em 2030 ficará entre 14,6 e 20 bilhões de barris e o déficit previsto será de 64 a $50 \%$ da demanda (T verberg, 2008).

E stes números mostram que a situação mundial será pouco alterada com as nossas descobertas no pré sal, mas que as mesmas poderão ser - mesmo sem o ufanismo lulista - um recurso precioso para o Brasil, se for usado para facilitar a transição do país para uma outra matriz energética não dependente de petróleo, gás ou carvão. Será preciso também mudar a matriz da demanda de energia na economia como um todo e em particular na agricultura.

O utros recursos naturais não renováveis são essenciais para o modelo do agronegócio. Fósforo e potássio são extraídos de minerais cujas jazidas também são tão finitas quanto as do petróleo, gás e carvão. 0 "pico do fósforo" ocorreu em 1989 e o do potássio deve ocorrer em 2040. Já o nitrogênio, elemento chave na adubação química, depende das já analisadas reservas de petróleo ou gás. 0 aumento nos custos de extração e 0 esgotamento de reservas fizeram com que os custos dos adubos químicos disparassem em 2008 no mercado internacional (D éry e Bart, 2007).

Os preços dos adubos fosfatados subiram de 259 USD/ton. em 2007 para 1.230 USD/ton. em julho de 2008. Os do potássio passaram de 172 para 500 USD / ton. e os dos adubos nitrogenados passaram de 277,00 para 450,00 U SD/ton. É claro que a alta dos preços do petróleo influenciou estas subidas, já que há custos energéticos na extração e transformação dos minérios em adubos químicos, mas é interessante notar que os preços dos adubos nitrogenados, os mais dependentes dos combustíveis fósseis, foram os que menos subiram no período, mostrando que o esgotamento das reservas de fósforo e as crescentes dificuldades na extração do potássio estão pesando mais no custo dos adubos. Essa análise da situação dos recursos naturais não renováveis, indispensáveis para a operação do agronegócio, permite afirmar que este é totalmente insustentável não em um remoto futuro, mas desde já.

\section{A INSUSTENTABILIDADE DO AGRONEGÓCIO}

Se incluirmos na análise os impactos do agronegócio sobre os recursos naturais renováveis, o nível de insustentabilidade deste sistema se acentua nitidamente. Segundo a FAO, 37\% dos cerca de 1,5 bilhões de ha de terras cultivadas no mundo já foram degradados desde a II Guerra Mundial. 0 impacto químico das práticas agrícolas responde por $40 \%$ desta degradação, os outros $60 \%$ sendo causados pela erosão pluvial ou eólica, pela compactação e pelo empobrecimento dos solos (Torres et al, 2000). N as áreas irrigadas, a degradação se dá pela salinização ou pelo encharcamento dos solos e a FAO aponta para uma degradação total de $13 \%$ e uma parcial de $33 \%$ nestas áreas em todo o mundo. N os EUA, a salinização afeta $28 \%$ das áreas irrigadas.

O s recursos hídricos também estão se esgotando pelo uso excessivo em irrigação. Aqüíferos "fósseis" com água depositada em grandes reservatórios no subsolo desde a última era glacial são reservas como o petróleo - não renováveis. Alguns dos maiores aqüíferos do mundo estão em processo de rápido esgotamento, sendo que 00 gallala, no meio-oeste americano, tem vida útil para mais 10 anos, no atual ritmo de extração de água. N o Brasil, 0 
aqüífero Guarani ainda é pouco explorado e dispõe de grandes reservas, mas não se pode, obviamente, contar eternamente com esta fonte (WORLD BAN K, 2008).

A perda da agrobiodiversidade, calculada pela $\mathrm{FAO} \mathrm{em}$ $75 \%$ das variedades de todas as plantas cultivadas ao Iongo do século passado, é outro fator de insustentabilidade, pois significa um brutal estreitamento da base genética das culturas. Esta homogeneização dos cultivos, agravada pela entrada em cena das variedades transgênicas, torna toda a agricultura altamente vulnerável a surtos de pragas, doenças e invasores. Estes surtos vêm se multiplicando e ampliando nas duas últimas décadas de tal forma que, apesar das milhões de toneladas de agrotóxicos hoje empregados pelo agronegócio, as perdas para estes "inimigos" das culturas cresceram de 28 para 37\%, desde a II Guerra M undial (CON WAY et PRETTY, 1991).

A insustentabilidade do sistema do agronegócio se reflete no seu balanço econômico. M esmo sem incluirmos os gigantescos custos das chamadas "externalidades" do sistema produtivo do agronegócio (contaminação de solos e águas, assoreamento de rios e lagos, envenenamento de trabalhadores e consumidores por agrotóxicos, emissões de gases de efeito estufa, desmatamento, chuvas ácidas, etc.), custos assumidos pelo E stado e pela sociedade como um todo, este sistema tem se mostrado economicamente inviável e só sobrevive com pesados subsídios diretos e indiretos.

Alguns dados col hidos aleatoriamente são indicativos desta realidade: (1) em 2002, os países da OCDE gastaram 320 bilhões de dólares em subsídios para o agronegócio; (2) em 1996, os EUA gastaram 70 bilhões de dólares com o mesmo fim; (3) o processo da criação do agronegócio brasileiro nos anos 70 recebeu subsídios de 50\% nos investimentos e custeio; (4) 0 agronegócio brasileiro recebeu anistias das dívidas com bancos públicos em 1998 e 2001 - esta última da ordem de 33 bilhões de reais - e está reivindicando uma nova anistia de 88 bilhões. Além disso, foram várias as operações de renegociação de dívidas implicando em ganhos para o agronegócio e perdas para o Estado. Essa situação de insolvência só tende a piorar com a deterioração/esgotamento dos recursos naturais renováveis ou não.

0 agronegócio vai enriquecer um pouco às custas do Estado e do futuro da humanidade ameaçada pela crise de abastecimento que não deixará de se abater sobre 0 mundo com o esgotamento crescente deste sistema. Para quem duvida deste desfecho basta notar o súbito aumen- to do número de famintos no mundo computado pela FAO, passando de pouco mais de 800 milhões em 2001 para 1 bilhão em 2009, apesar da meta de redução do primeiro número à metade em 2015.

U m terceiro elemento importante para definir a sustentabilidade tampouco é incorporado nas definições acima mencionadas: a sustentabilidade social. Se faz referência muitas vezes à necessidade da agricultura sustentável ser "socialmente justa", mas não há nenhuma explicação sobre o que isto quer dizer e porque é importante para a sustentabilidade.

Especulando sobre o conceito podemos perguntar se a sustentabilidade social significa que os camponeses devem ser os principais ou únicos atores deste modelo de agricultura. Isto só seria verdade se a agricultura empresarial fosse, por natureza, insustentável ese a agricultura camponesa fosse, também por natureza, sustentável. $\mathrm{N}$ a realidade, a primeira premissa é verdadeira, mas a segunda não o é, necessariamente.

A agricultura empresarial é insustentável por natureza por empregar insumos que dependem de recursos naturais não renováveis, por destruir os recursos naturais renováveis e por desequilibrar o meio ambiente com suas monoculturas em grande escala. U m exemplo claro do que deverá acontecer com este modelo agroquímico e motomecanizado ocorreu quando da dissolução do bloco soviético. 0 impacto da queda do muro de Berlim sobre a agricultura cubana foi devastador. Os cubanos dependiam dos países do leste para obter petróleo e insumos para suas empresas estatais de produção agrícola e, de uma hora para outra, deixaram de ter acesso a estes recursos. 0 s tratores e colheitadeiras pararam e faltaram adubos químicos e agrotóxicos. A produção despencou e o país foi submetido a um drástico racionamento de alimentos (H einberg, 2006).

\section{A AgRICULTURA CAMPONESA E A AGROECOLOGIA}

A agricultura camponesa, se depender da mesma base tecnológica do modelo da revolução verde viverá o mesmo problema. No entanto, também é evidente que 0 modo de produção camponês tradicional não é capaz de responder às demandas da população mundial, mesmo em condições ideais.

O s sistemas tradicionais de produção camponesa foram sustentáveis enquanto tiveram espaço suficiente 
para deixar grandes áreas em pousio para permitir a regeneração natural da fertilidade dos solos. Com 0 aumento da população, a necessidade de terras impediu que os tempos de pousio fossem suficientes para que esta recuperação ocorresse e as produtividades foram caindo pouco a pouco. M esmo em condições ideais, estas produtividades nunca foram suficientemente elevadas para cobrir as crescentes demandas de alimentos. Alguns sistemas produtivos camponeses adotam formas engenhosas de fertilização das culturas, mesmo sem 0 emprego de adubos químicos, mas as necessidades de aumento de produção mostraram as limitações destas alternativas. No entanto, não se devem desprezar estes sistemas mais elaborados, pois os mesmos, freqüentemente, conseguiram produtividades significativas de forma sustentável. 0 grande diferencial destes sistemas em relação aos da revolução verde não foi na produtividade dos solos, mas na produtividade do trabalho.

A progressiva desaparição do campesinato, ao longo do século passado, nos países desenvolvidos, mas também em muitos países em desenvolvimento, como 0 Brasil, vem levando ao esvaziamento das zonas rurais e à concentração da população nas cidades. Este fenômeno é mundial e, recentemente, o marco da superação dos habitantes das zonas rurais pelos das zonas urbanas foi alcançado. M uitos analistas não só consideram este processo como inexorável como também um indicador de "progresso". M as, à luz da crise energética em progressão o esvaziamento do campo e a desaparição do campesinato não são notícias alvissareiras. Se a produção em larga escala do sistema do agronegócio vai se tornar inviável, quem vai produzir alimentos?

A questão da sustentabilidade social está fortemente vinculada a escolhas tecnológicas que permitirão a produção física sustentável. 0 sistema produtivo em gestação que responde aos critérios de sustentabilidade colocados acima chama-se agroecologia e vem mostrando 0 seu potencial em várias partes do mundo.

A agroecologia minimiza o uso de recursos naturais não renováveis e pode chegar a eliminá-los; conserva e, se necessário, recupera os recursos naturais não renováveis; é econômica no uso de água; tem balanço energético positivo; absorve gases de efeito estufa, integra a vegetação natural no equilíbrio dos agroecossistemas; não polui 0 ar, o solo e os recursos hídricos. Em outras palavras, responde a todos os problemas de insustentabilidade encontrados no modelo do agronegócio.

Analistas mal informados sustentam que a produção agroecológica ou a orgânica (uma variante não necessariamente sustentável) tem produtividades mais baixas e não é capaz de suprir as necessidades da demanda mundial de alimentos e de outros produtos agrícolas, e forçaria 0 aumento dos desmatamentos para abrir espaço para 0 aumento de produção. $\mathrm{N}$ ada mais falso. Várias pesquisas, como a realizada pelo $\mathrm{C}$ onsel ho $\mathrm{N}$ acional de Ciências dos Estados U nidos, já nos anos 80, indicaram que se toda a agricultura americana se convertesse aos sistemas orgâni cos não haveria desabastecimento no país. As produtividades de quase todas as culturas estudadas foram similares às obtidas em sistemas convencionais e os preços mais altos dos produtos orgânicos foram atribuídos não a maiores custos de produção, mas à pouca oferta e alta demanda, bem como aos custos de comercial ização. Pesqui sas mais recentes realizadas pela FAO indicaram que, se toda a agricultura do mundo se convertesse aos sistemas orgânicos, a quantidade de calorias produzida variaria entre 2800 e 4300 por pessoa por dia, dependendo das hipóteses formuladas (H elweil, 2006). Em sistemas agroecológicos, em geral mais produtivos do que a maioria dos sistemas orgânicos, os resultados seriam ainda mais promissores. Para dar alguns dados significativos, lembramos que sistemas de produção de arroz agroecológico em Madagascar alcançaram até 22 toneladas por hectare, com médias de 12 toneladas nas etapas de transição (U phoff, 1999). Sistemas de manejo agroecológico de pastagens nos E stados U nidos al cançaram 2 tonel adas de carnes de boi, carneiro e aves por hectare. Produtividades de soja, milho e feijão em sistemas agroecológicos no estado do Paraná al cançaram, respectivamente, 3200, 3000 e 9000 quilos por hectare, bem acima das médias do estado².

\section{DESAFIOS PARA A SUSTENTABILIDADE D O MODELO AGROE- COLÓGICO}

0 "ponto fraco" da agroecologia é a sua escala de produção. $\mathrm{N}$ a agroecologia trabalha-se com sistemas de

\footnotetext{
2 Observações do autor.
} 
alta diversidade de culturas e criações, sistemas complexos no uso do espaço e na organização do trabalho. São ainda sistemas intensivos no uso de conhecimentos e exigentes na qualidade da mão de obra. Por estas razões trata-se de um sistema que não se adapta ao uso de mão de obra assalariada nem de mecanização em larga escala. A agroecologia se adapta perfeitamente a um sistema agrário baseado na agricultura familiar, operando em escalas que variarão de acordo com o grau de complexidade do sistema produtivo e com a disponibilidade e qualidade da mão de obra familiar.

U m sistema produtivo baseado na agroecologia e na agricultura familiar necessitará de muitos camponeses. $\mathrm{N}$ ão só o número será importante, mas também a experiência prévia deste campesinato. A complexidade da agroecologia e a sua própria natureza a aproxima dos sistemas tradicionais, muito embora empregue conhecimentos mais amplos, gerados também pela ciência e pela inovação camponesa. A experiência mostra que um agricultor tradicional aprende mais rapidamente os princípios e práticas da agroecologia do que os formados no paradigma da revolução verde. É por esta razão que o esvaziamento do campo e a perda do conhecimento camponês sobre seu agroecossistema dificultam a necessária e inevitável transição dos sistemas atuais para os sistemas agroecológicos. Como apontado acima, esta éa natureza do critério de sustentabilidade social: sem uma numerosa e bem preparada classe de camponeses não haverá agricultura sustentável.

Para concluir, a articulação dos diferentes critérios de sustentabilidade da agricultura depende das opções tecnológicas adotadas, e estas vão condicionar o tipo de agricultor mais indicado para realizá-la. A agroecologia, aplicada pela agricultura familiar ou camponesa, é a forma de produção que permite garantir a sustentabilidade ecológica, energética, econômica e social.

\section{REFERÊNCIAS BIBLIOGRÁFICAS}

TVERBERG GAIL, E. Peak Oil 0 verview - June2008, Energy Bulletin, Junho de 2008. Disponível em < http://www. energybulletin.net/node/45681>

CON WAY, G .R.; PRETTY, J.N .U nwelcomeharvest: agricultureand pollution. L ondow: Earthscan, 1991.645p.

DÉRY, P.; AN D ERSON , B. Peak Phosphoros. Energy Bulletin. 13deAgosto de2007. D isponível em < http://www.energybulletin. net/node/33164> . Acesso em

TORRES, F.; PIÑEIRO, M.; TRIGO, E.; N OGUEIRA, R.M. Agriculturein theearly XXI Century: Agrodiversity and Pluralism asaC ontribution to Address I ssues on Food Security, Poverty and $\mathrm{N}$ atural Resource Conservation Reflections on its $\mathrm{N}$ ature and Implicationsfor G lobal Research. G lobal Forum on A gricultureResearch, Rome, jul ho de 2000.

HEIN BERG, R. FiftyM illion Farmers. EnergyBulletin, 17/11/2006.

HELWEIL, B. Can organicFarming Feed theWorld? Worldwatch Magazine. Maio/J unho 2006.

ZIM M ERM AN N , M. O ver a barrel; what if oil hits $\$ 200$ ? L oS AngelesT imes, 28/6/2008.

PORT 0, M. 0 crepúsculo do Petróleo, Brasport, 2006, p. 28.

UPH OFF,N . Agroecological Implications of theSystem of Rice Intensification (SRI) in M adagascar. In: Environment, D evelopment and SustainabilityK K luwer A cademicPublishers. v. 1, n. 3-4, p. 297, 1999.

WORLD BAN K. World development report 2008: agriculture for development. Washington, 2008. 